\title{
Predictors of the Persistence of Male Aggression in Early Marriage ${ }^{1}$
}

\author{
Michael F. Lorber ${ }^{2,4}$ and K. Daniel O'Leary ${ }^{3}$
}

\begin{abstract}
The prediction of husband-to-wife physical aggression was examined in a sample of 94 community couples in which the husband had engaged in at least one act of physical aggression toward his partner during the engagement period. Predictors were measured approximately one month prior to marriage, and physical aggression was assessed again at 6, 18, and 30 months postmarriage. Over seventy-six percent of the men who were physically aggressive during the engagement period were physically aggressive at one or more of the next three assessments across the initial 30 months of marriage. Nearly $62 \%$ were severely aggressive at one or more assessments. Results were generally supportive of the hypothesis that risk factors for persistent antisocial behavior would predict the persistence of aggression. More frequent physical partner aggression, aggressive personality styles, general aggression, and witnessing interparental aggression in the family of origin were associated with continued aggression. Only general aggression, and premarital physical aggression predicted the persistence of severe aggression.
\end{abstract}

KEY WORDS: domestic violence; persistence; longitudinal; antisocial.

The stability of aggression is thought to rival that of intelligence (Olweus, 1979). Evidence suggests that partner violence is not an exception (e.g., Capaldi et al., 2003). Moreover, there is emerging evidence that maleto-female aggression in couples is quite persistent. For example, in a small sample of men recruited because they were severely aggressive, Jacobson et al. (1996) found that $46 \%$ remained severely violent two years later. Further, only $7 \%$ ceased their use of physical aggression altogether. In a sub-sample of severely aggressive men selected from a larger nationally representative sample, Feld and Straus (1989) found that $57 \%$ of the severely aggressive men continued to engage in such aggression at year 2. Despite the considerable degree of persistence in clinical

\footnotetext{
${ }^{1}$ Portions of the findings reported in this manuscript were presented at the 34th Annual Meeting of the Association for Advancement of Behavior Therapy, New Orleans, LA (November, 2000).

${ }^{2}$ Institute of Child Development, University of Minnesota, Minneapolis, MN.

${ }^{3}$ Department of Psychology, State University of New York at Stony Brook, Stony Brook, New York.

${ }^{4}$ To whom correspondence should be addressed at Department of Psychology, SUNY-Stony Brook, Stong Brook, NY 11794-2500; e-mail: doleary@notes.cc.sunysb.edu.
}

populations, physical aggression toward a partner decreases across the life span in nonclinical populations (O’Leary, 1999; Suitor et al., 1990).

Persistence of physical aggression is an important, but under-researched topic. The consequences of persistent aggression are likely to be especially serious, as domestic violence is associated with a number of adverse consequences for women such as depression, posttraumatic stress disorder, and suicide attempts (Campbell et al., 1997; Crowell \& Burgess, 1996). Identifying which men are at risk for continued aggression is clinically important. Advice to young individuals about to marry might be qualified by admonitions about the persistence of physical aggression in intimate relations and the meaning of such aggression for the relationship. Clinicians would benefit from enhanced prediction of later aggression, especially if the prediction were derived from practical assessment materials.

We currently know very little about what is predictive of the persistence of aggression. The authors are aware of only four published studies of the prediction of the persistence of marital aggression. Feld and Straus (1989) found that frequency of severe assault increased 
the probability of partner aggression 1 year later. Jacobson et al. (1996) found that men who remained severely violent over a period of 2 years were more domineering, globally negative, and emotionally abusive toward their wives in a laboratory interaction at the initial assessment. Aldarondo and Sugarman (1996) divided violent men into two groups: those who ceased aggressing for 2 of the 3 years over which they were assessed, and those who persisted. Persistently aggressive men were of lower socioeconomic status and had higher initial levels of marital conflict. Lastly, Quigley and Leonard (1996) found that men who were more likely to persist in their physical aggression over a 3-year period were more aggressive toward their wives in the first year of marriage.

At present, the literature on the persistence of couple aggression is small. Furthermore, research and theory in this area would be enhanced by tying it to more mature literature on phenomena related to aggression. Clues from the literature on the development of antisocial behavior may be helpful in generating predictions about which men will be more likely to exhibit more persistent aggression toward their partners. We now briefly review this literature in order to provide a context for hypotheses of the present research.

\section{THE DEVELOPMENT OF PERSISTENT ANTISOCIAL BEHAVIOR}

Theory on the development of antisocial behavior has identified a set of interpersonal and environmental factors that are thought to increase the risk of persistent antisocial behavior (see Loeber \& Stouthamer-Loeber, 1998; Lynam, 1996; Moffitt, 1993). Longitudinal data has begun to support these hypotheses. For example, Moffitt and Caspi (2001) reported that factors, including harsh parenting, family conflict, and the degree of aggressiveness, were associated with persistent antisocial behavior. Elkins et al. (1997) reviewed several longitudinal studies, the results of which suggest that variables such as impulsivity and substance abuse/dependence are risk factors for persistent antisocial behavior as well.

An important characteristic of the literature on persistent antisocial behavior is its emphasis on how persistently antisocial individuals are surmised to represent a naturally occurring group (taxon) that is distinct from time-limited antisocials. Differences in presumably innate and environmental factors, and their interaction (e.g., difficult temperament combined with inept parenting; Moffitt, 1993), appear to differentiate these groups early in life. These early differences are associated with the trajectory of antisocial behavior. For example, Huesmann et al. (1984) found that 8-year-old boys identified as aggressive were more likely to commit serious criminal acts, abuse their spouses, and drive while intoxicated, as adults.

\section{THE PRESENT INVESTIGATION}

We hypothesized that risk factors for persistent antisocial behavior would be predictive of the persistence of partner aggression. These hypotheses were tested in a community sample of young heterosexual couples with physically aggressive males who were followed from premarriage through the first 30 months of their marriages. Subjects were drawn from data archived from previous research in which multiple couple- and individual-level variables were assessed (O'Leary et al., 1989, 1994). Relevant predictors from this data set included aggressive and impulsive personality styles, problem drinking, general aggression, the degree of physical partner aggression, as well as retrospective reports of interparental aggression witnessed and child abuse experienced in the family of origin. All predictors were assessed at premarriage. We operationalized persistence as the number of assessments at which physical aggression was present, measured on four occasions (1 month premarriage, and 6, 18 , and 30 months postmarriage). This operationalization created ordered categories that were relatively heterogeneous in terms of their aggression severity. To explore the performance of our set of risk factors in predicting the persistence of severe physical aggression, analyses were repeated in a sub-sample of men who were severely aggressive at premarriage.

We wish to emphasize that the current research is not typological or taxonic (i.e., we are not concerned with differentiating naturally occurring groups of aggressors). Instead, we believe that persistence of couple aggression can be seen as a dimensional construct; that persistence exists on a continuum.

\section{METHOD}

\section{Participants}

Participants were drawn from a community sample of couples $(N=396)$ planning marriage between 1983 and 1986 in Onondaga and Suffolk counties, NY. Couples were recruited via newspaper and radio announcements of a study of first marriages designed to contribute to knowledge of marriage and the family. Each couple received a total of $\$ 160$ for its participation across all four assessments. Further details on recruitment of the sample have been reported elsewhere (O'Leary et al., 1989). For 
the present analyses, only couples who participated at all four assessment points $(N=238)$, and in which the husband was physically aggressive at the initial assessment $(N=94)$, were retained. ${ }^{5}$ The 94 men who were aggressive at Time 1 were White, had a mean age of 25.29 years $(S D=3.85)$ and a length of engagement of 13.35 months $(S D=8.68)$. They had an average of 14.57 years of college education $(S D=2.42)$, and had a mean income of $\$ 18,640(S D=\$ 6,958.88)$.

\section{Procedure}

Participants were assessed 4 times: at approximately 1 month premarriage and at 6,18 , and 30 months after marriage. At each of their visits, they completed a packet of questionnaires. Spouses completed the questionnaire packets in separate rooms or in the same room with a research assistant present to ensure confidentiality. At each assessment, couples were assured that their responses would be kept confidential.

\section{Measures}

\section{Conflict Tactics Scale (CTS)}

The CTS (Straus, 1979) is a widely used 18 -item self-report inventory that measures the frequency of conflict tactics, ranging from functional (e.g., calmly discussing a problem), to verbally (e.g., insults or swearing) and physically (e.g., hitting) aggressive conflict tactics. We calculated three husband-to-wife physical aggression scores: 1) the frequency of male-to-female physical aggression at premarriage (Cronbach's alpha $=.77), 2$ ) the total number of assessments at which each man was physically aggressive, and 3) the total number of assessments at which each man was severely physically aggressive. The later two variables reflect our operationalization of the persistence of aggression, the dependent variables. Physical aggression comprised items from the mild and severe aggression subscales of the CTS. Mild aggression included the following items: 1) throwing something at the partner, 2) pushing, grabbing, or shoving, and 3) slapping. Severe aggression included the following items: 1) kicking, biting, or hitting with a fist, 2) hitting or trying to hit with something, 3) beating up, 4) threatening with a gun or knife, and 5) using a gun or knife.

Both men and women are more likely to report being the recipient of violence than being the aggressor

\footnotetext{
${ }^{5}$ Seventy-six men from the larger sample who were aggressive at Time 1 were not available at all four assessment points, and were thus excluded.
}

(Browing \& Dutton, 1986). Therefore, in the computation of the frequency of premarital physical aggression, husbands' reports of perpetration and wives' reports of victimization were averaged. Also, husbands were classified as physically aggressive at each assessment if either member of the couple reported at least one act of husbandto-wife physical aggression in the previous year (or in the last 6 months, in the case of the second assessment).

\section{Michigan Alcohol Screening Test (MAST)}

The MAST (Selzer, 1971) is a widely used measure of the physical, social, and psychological consequences of problem drinking. Scores range from 0 to 53, with a score of 8 or more indicative of problem drinking. The MAST differentiates men in control groups from those convicted of drunk driving and of drunk and disorderly conduct, and from those hospitalized for alcoholism (Selzer, 1971). Cronbach's alpha for the present sample was .82.

\section{Jackson Personality Research Form-E (PRF)}

The PRF (Jackson, 1974) is a self-report measure comprising 22 scales. Each scale contains 16 true-false items, half of which are reverse scored. The aggressive personality and impulsivity scales were used in the present study. The aggressive personality scale measures behavioral tendencies to act angrily, argumentatively, or vengefully (e.g., starting fights, feeling like smashing things, feeling like hitting someone; $\alpha=.64$, in the present investigation). The impulsivity scale measures behavioral tendencies to act hastily, spontaneously, recklessly, and impetuously (e.g., saying the first thing that comes to mind, acting recklessly, not thinking ahead; $\alpha=.80$, in the present investigation). Both scales have good testretest reliability (.63-.74 and .77-.85, respectively) and convergent validity (e.g., moderate to strong correlations with peer ratings of the subject; Jackson, 1974).

\section{Family of Origin and General Aggression}

The Family Violence Questionnaire (Riggs \& O'Leary, 1996) was used to assess respondents' memories of family of origin child abuse victimization, interparental aggression witnessed, as well as selected current deviant self and spouse behavior. For purposes of the present study, three variables were created: 1) child abuse victimization, 2) witness of interparental violence, and 3) current general aggression. Child abuse was calculated as the sum of seven items representing the experience of abusive parenting (e.g., hitting, beating, causing bruises or 


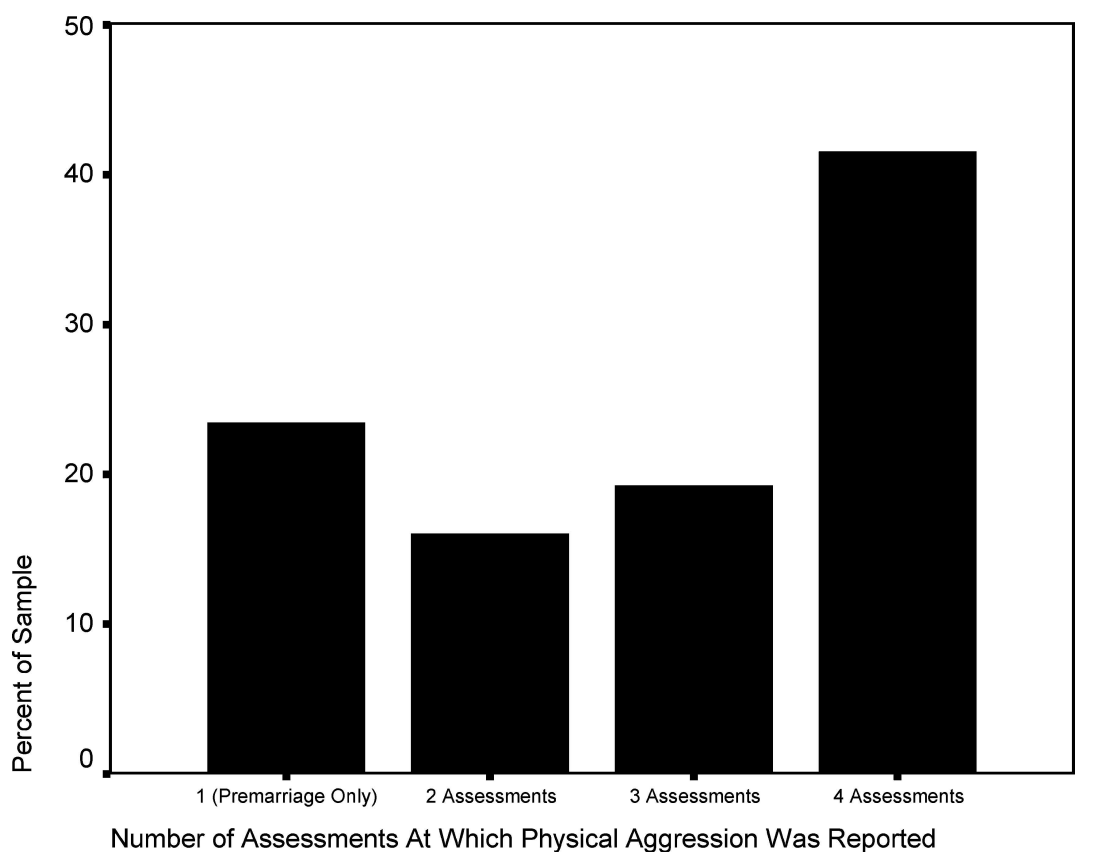

Fig. 1. The distribution of physical aggression persistence in men who were physically aggressive at premarriage, as reported by the husband and/or wife.

cuts; $\alpha=.72$ ). The witnessing interparental violence variable was calculated as the sum of three items representing the respondent's memory of interparental aggression (e.g., how often his father hit his mother, how often his mother beat his father; $\alpha=.60$ ). General aggression was the sum of scores on two items: the respondent's current tendency to (1) fight and (2) argue with others.

\section{RESULTS}

\section{Analytic Strategy}

The dependent variables-number of assessments at which men were physically aggressive and severely aggressive (i.e., persistence of aggression) — are ordinal variables. Because the intervals between assessments were unequal ( 7,12 , and 12 months), the difference in persistence between a score of 2 and 3, for example, is not the same as between 3 and 4 . As such, the data violate the assumption of interval or ratio level data common to parametric statistical tests (e.g., ordinary least squares estimation). Furthermore, as there are only 4 possible scores on each of the criterion variables, ties are a significant issue. Thus, we used a combination of a) tie-corrected ordinal correlations (Kendall's $t a u-b$ ) to assess the bivariate relations of each predictor and aggression persistence, and b) multinomial logistic regression, to explore the unique contribution of each of these variables to the prediction of the persistence of aggression. Although the use of ordinal correlations was necessitated by our dependent variables (aggression and severe aggression persistence), they had the unfortunate effect of sacrificing the sensitivity of our continuous predictors. Thus, our analyses are conservative.

The percentage of missing predictor data ranged from 0-7\%. NORM (Schafer, 1999), a program for multiple imputation of incomplete multivariate data, was used to impute missing values.

\section{Descriptive Analyses}

There were 399 men in total in the sample, and 94 of those men had data at all three remaining assessments and were physically aggressive at premarriage. Of these 94 men, $22(23.40 \%)$ were physically aggressive at only the premarriage assessment; $15(15.96 \%)$ were physically aggressive at one of the three remaining assessments; 18 of the men (19.15\%) were physically aggressive at two of the remaining assessments; and 39 $(41.45 \%)$ of them were aggressive at all three additional assessments (see Fig. 1). The specific assessment points at which men who were aggressive at two total time points were fairly evenly distributed, $\chi^{2}(2, N=15)=.40, n s$. 
The distribution of which assessment points men who were aggressive at three time points aggressed at also did not differ from chance, $\chi^{2}(2, N=18)=2.33$, ns. The distribution of frequencies across persistence categories differed from chance, $\chi^{2}(3, N=94)=14.68, p<.01$. Relative to chance, there were fewer than expected men at the lower three levels of persistence, and more than expected in the most persistent group. A substantial minority was severely aggressive at premarriage $(N=35$, $37.23 \%)$. However, in the first 30 months of marriage, $61.70 \%$ of the men in the study $(N=58)$ were severely aggressive.

Of the 35 men who were severely aggressive at premarriage, $11(31.43 \%)$ were severely aggressive at the premarriage assessment only, with $10(28.57 \%), 8$ $(22.86 \%)$, and $6(17.14 \%)$ severely aggressive at 1,2 , and 3 of the remaining assessments, respectively (see Fig. 2). Thus, the majority of these men $(82.86 \%)$ had-at least temporarily-desisted their severe aggression by the end of the study. The distribution of frequencies did not differ significantly from chance $\left(\chi^{2}(3, N=35)=1.69\right.$, $n s)$. The specific assessment points at which men who were severely aggressive at two total time points were fairly evenly distributed. Note that chi-square cannot be computed here due to expected frequencies below 5 . The distribution of which assessment points men who were severely aggressive at three total time points severely aggressed at was more uneven. More than half (57.14\%) of these men were severely aggressive at premarriage, 6 , and 30 months; $28.57 \%$ were severely aggressive premarriage, 18 , and 30 months; only one man was severely aggressive at premarriage, 6 , and 18 months.

Physical aggression, as well as impulsivity, child abuse victimization, witnessing interparental aggression, and problem drinking were positively skewed. Physical aggression was natural log transformed, impulsivity was square root transformed, and child abuse and problem drinking were log (base 10) transformed. The distribution of interparental aggression indicated that there were essentially two groups: men who witnessed interparental aggression, and those who did not. Interparental aggression was dichotomized accordingly.

\section{Bivariate Relations}

\section{Persistence of Aggression}

Frequency of physical aggression at premarriage $(r=.33, p<.001)$, aggressive personality styles $(r=$ $.21, p<.01)$, general aggression $(r=.21, p<.05)$, and

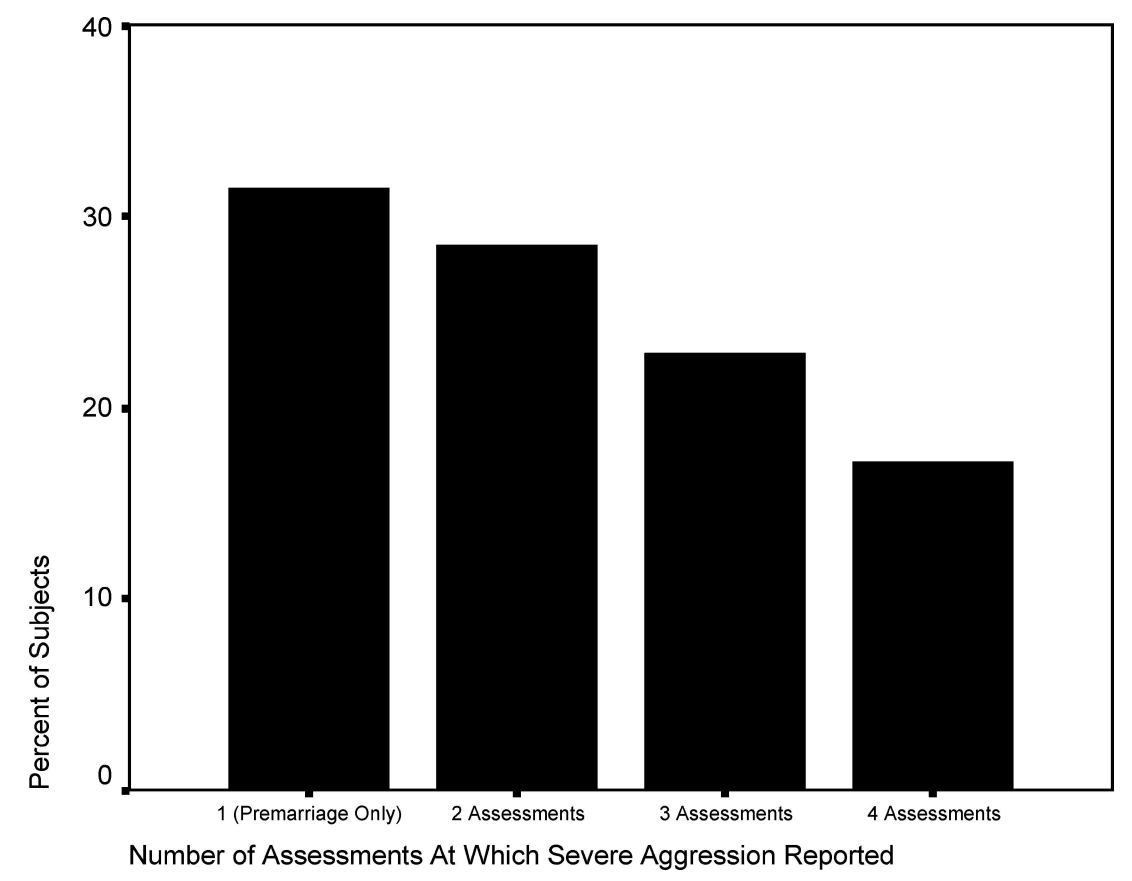

Fig. 2. The distribution of severe physical aggression persistence in men who were severely physically aggressive at premarriage, as reported by the husband and/or wife. 
Table I. Bivariate Prediction of Aggression Persistence

\begin{tabular}{|c|c|c|c|c|c|c|c|}
\hline & 1 & 2 & 3 & 4 & 5 & 6 & 7 \\
\hline 1. Aggression persistence & - & & & & & & \\
\hline 2. Physical aggression ${ }^{a}$ & $.33^{* * *}$ & - & & & & & \\
\hline 3. Aggressive personality & $.21^{* *}$ & .18 & - & & & & \\
\hline 4. Impulsive personality ${ }^{b}$ & .04 & .10 & .16 & - & & & \\
\hline 5. General aggression & $.21^{*}$ & .04 & .23 & .09 & - & & \\
\hline 6. Child abuse ${ }^{c}$ &.$\overline{.08}$ & .10 & .17 & .21 & .19 & - & \\
\hline 7. Interparental aggression ${ }^{d}$ & $.19^{*}$ & .16 & .16 & -.03 & .13 & .23 & - \\
\hline 8. Problem drinking ${ }^{c}$ &.$\overline{.06}$ & .30 & .25 & .16 & .41 & .21 & .22 \\
\hline
\end{tabular}

Note. $N=94$; Coefficients with aggression persistence are Kendall's tau-b; All other correlations are zero-order; Analyzed correlations are underlined (one-tailed significance tests).

${ }^{a}$ Natural log transformed.

${ }^{b}$ Square root transformed.

${ }^{c} \log$ transformed.

${ }^{d}$ Dichotomized.

${ }^{*} p<.05 .{ }^{* *} p<.01 .{ }^{* * *} p<.001$.

witnessing interparental aggression $(r=.19, p<.05)$ were significantly and positively correlated with the persistence of aggression (see Table I). Impulsivity, child abuse, and problem drinking were not significant predictors. All significance tests were one-tailed due to the directional nature of the hypotheses.

\section{Persistence of Severe Aggression}

Only the frequency of physical aggression at premarriage $(r=.27, p<.05)$ and general aggression at premarriage $(r=.42, p<.05)$ were significant (onetailed) predictors of the persistence of severe aggression (see Table II). Note that, the magnitude of the relation of general aggression and severe aggression persistence was larger than in the prediction of the persistence of aggregate physical aggression. However, this could not be evaluated statistically because the samples were partially overlapping.

The nonsignificance of the other predictors did not appear to be due to range restriction or low statistical power inherent in the small sample ( 35 men were severely aggressive at engagement). All nonsignificant correlations with severe aggression persistence were below .15 .

\section{Multivariate Prediction}

Multinomial regression is used for analyses with categorical criterion variables and either continuous and/or categorical predictors. It provides four sources of statistical information: 1) overall model fit, 2) percentage correct classification in each category, 3) unique contribution of
Table II. Bivariate Prediction of Severe Aggression Persistence

$\begin{array}{lllllll}1 & 2 & 3 & 4 & 5 & 6 & 7\end{array}$

1. Severe aggression persistence

2. Physical aggression ${ }^{a}$

3. Aggressive personality

4. Impulsive personality ${ }^{b}$

5. General aggression

6. Child abuse ${ }^{c}$

7. Interparental aggression ${ }^{d}$

8. Problem drinking ${ }^{c}$

$\begin{array}{lllllllll}\overline{.27^{*}} & - & & & & & \\ \frac{.00}{.13} & .12 & - & & & & \\ \underline{.13} & .12 & .46 & - & & & \\ \underline{.42} & .27 & .20 & .22 & - & & \\ \underline{.08} & .10 & .31 & .38 & .17 & - & \\ \underline{.13} & .28 & .11 & .30 & .00 & .34 & - \\ \underline{.14} & .48 & .26 & .22 & .44 & .19 & .22\end{array}$

Note. $N=35$; Coefficients with severe aggression persistence are Kendall's tau-b; All other correlations are zero-order; Analyzed correlations are underlined (one-tailed significance tests).

${ }^{a}$ Natural log transformed.

${ }^{b}$ Square root transformed.

${ }^{c}$ Log transformed.

${ }^{d}$ Dichotomized.

${ }^{*} p<0.5$.

each predictor to overall discrimination among levels of the criterion, and 4) unique contribution of each predictor to the discrimination among a reference category and each other category of the criterion variable.

Multinomial regression analyses (see Table III) revealed significant combined prediction of the persistence of aggression, $\chi^{2}(21, N=94)=56.76, p<.001$. Overall accuracy of classification of men into one of the four aggression persistence categories was $59.77 \%$. We were best able to predict which men would be most and least persistently aggressive, with $55.45 \%$ (chance $=29.67 \%$ ), $30.67 \%($ chance $=21.37 \%), 46.67 \%($ chance $=27.22 \%)$, and $79.49 \%$ (chance $=49.09 \%$ ) accuracy for predicting whether men were physically aggressive at one, two, three, or at all four assessments, respectively.

Table III. Multivariate Prediction of the Persistence of Aggression

\begin{tabular}{lccrc}
\hline & & \multicolumn{3}{c}{ Regression coefficient } \\
\cline { 3 - 5 } \multicolumn{1}{c}{ Predictor } & LR $\chi^{2}$ & $4: 1$ & $4: 2$ & $4: 3$ \\
\hline Physical aggression $^{a}$ & $18.58^{* * *}$ & $8.57^{* *}$ & 2.00 & 2.16 \\
Aggressive personality & 6.50 & .21 & .10 & $.26^{*}$ \\
Impulsive personality $^{b}$ & 5.70 & .10 & .43 & $1.03^{*}$ \\
General aggression & 7.84 & .96 & $2.01^{*}$ & .32 \\
Child abuse $^{c}$ & $9.76^{*}$ & 3.03 & -6.62 & $-14.15^{*}$ \\
Interparental aggression $^{d}$ & 6.91 & 7.13 & 4.08 & 5.41 \\
Problem drinking $^{c}$ & 4.42 & $-8.16^{*}$ & -1.09 & -.44 \\
\hline
\end{tabular}

Note. $\chi^{2}(21, N=94)$ for overall model fit $=56.76, p<.001$.

${ }^{a}$ Natural log transformed.

${ }^{b}$ Square root transformed.

${ }^{c} \log$ transformed.

${ }^{d}$ Dichotomized.

${ }^{*} p<.05 .^{* *} p<.01 .{ }^{* * *} p<.001$. 
Likelihood ratio tests (with one degree of freedom) indicated that premarital physical aggression $(p<.001)$ and the experience of child abuse $(p<.05)$ uniquely contributed to the overall distinction among levels of the persistence of partner aggression. Physical aggression was uniquely associated with more persistent aggression as indicated by positive regression coefficients. Higher levels of child abuse victimization, however, were related to less persistent partner aggression, as indicated by negative coefficients. Regression coefficients ${ }^{5}$ represent the -2 log-odds of being in the highest (aggressive at all 4 assessments) category vs. each of the lower categories (aggressive at 1,2, or 3 assessments).

Multinomial analyses were not performed for the prediction of severe aggression because there were only 35 men who were severely aggressive at premarriage.

\section{DISCUSSION}

We drew on literature on the development of antisocial behavior to make longitudinal predictions about the persistence of male physical aggression in early marriage. It was hypothesized that risk factors associated with persistent antisocial behavior (Elkins et al., 1997; Loeber \& Stouthamer-Loeber, 1998; Lynam, 1996; Moffitt, 1993; Moffitt \& Caspi, 2001) would predict the persistence of male-to-female violence. Community couples in which the man was identified as physically aggressive 1 month prior to marriage were reassessed at 6,18 , and 30 months postmarriage for the presence of continued physical aggression. Predictors included premarital measures of personality characteristics, physical aggression, general aggression, problem drinking, and retrospective reports of violence in the family of origin.

Before examining predictors of the persistence of physical aggression, we first examined the degree of persistence of physical aggression in this sample. In our previous research we had examined the conditional probabilities of self-reported physical aggression at 18 months, given any physical aggression at pre-marriage (.51), and the conditional probabilities of physical aggression at 30 months, given any physical aggression at 18 months (.59; O'Leary et al., 1989). However, we had never assessed the persistence of physical aggression by looking at the percentages of men who were physically aggressive at each of the four assessments, using both husband and wife reports. We were frankly surprised at the amount of persistence when examined in this fashion: over $76 \%$ of

\footnotetext{
${ }^{5}$ Note that, as with ordinary least squares regression, individual coefficients are dependent on the scale of measurement of the predictor.
}

the men who were physically aggressive at pre-marriage aggressed at one or more of the remaining assessments. Further, even more surprising was the finding that $41 \%$ of the men who were aggressive at pre-marriage were physically aggressive at all of the next three assessments. What is more, while approximately $37 \%$ of the men in our sample were severely aggressive at premarriage, when followed over the first 30 months of their marriages, almost $62 \%$ of the entire sample of community aggressors were severely aggressive at some point.

Given the extent of persistence in this community sample of young married individuals, one can use these data to suggest to young community men and women that what may even seem like inconsequential aggression to many is actually a sign that physical aggression-even severe aggression-will occur for most couples at some point in the future. In looking at reports of both partners, as well as looking at a time period from premarriage to 30 months after marriage, physical aggression of men who were aggressive at premarriage was in fact quite persistent, with severe aggression far in excess of chance.

We then evaluated the individual relation of each Time 1 (premarriage) predictor and the persistence of physical aggression, operationally defined as the number of assessments at which the husband was aggressive. As hypothesized, more frequent physical aggression at premarriage, aggressive personality styles, general aggression, and witnessing interparental aggression in the family of origin emerged as significant predictors of continued aggression over the first 2.5 years of marriage. However, impulsivity, child abuse in the family of origin, and problem drinking did not contribute to the bivariate prediction of persistent aggression.

We next examined multivariate prediction of the persistence of aggression and found that the Time 1 measures were jointly predictive of aggression persistence. While overall accuracy of classifying the degree of persistence was approximately $60 \%$, prediction was notably better for the most and least persistently aggressive men (prediction exceeded chance by approximately $26 \%$ and $30 \%$, respectively). The predictive accuracy for men who were aggressive at two and three of the assessments exceeded chance by approximately $9 \%$ and $19 \%$, respectively. The lower predictive accuracy for these men may reflect heterogeneity produced as a byproduct of our variable construction. For example, men who were aggressive at premarriage and the last follow-up, as well as those who were aggressive at only the first two assessments fell into the same category (i.e., aggressive at two time points). In contrast, all aggression was reported at identical time points, within the groups of men who were aggressive at one or four time points. 
The degree of premarital physical aggression and child abuse in the family of origin emerged as unique predictors of aggression persistence. Higher levels of physical aggression toward the fiancé were independently associated with the persistence of aggression. However, with all of the other predictors statistically controlled, higher levels of child abuse appear to have contributed to less, rather than more, persistent aggression. This counterintuitive relation was contrary to our hypotheses. The predicted consequence of child abuse victimization would be risk for the development of antisocial-spectrum behavior (see Moffit, 1993). However, child abuse is also associated with the development of anxiety disorders, such as PTSD (e.g., Boney-McCoy \& Finkelhor, 1996). Anxiety is associated with behavioral avoidance-flight rather than fight. Therefore, once the overlap with antisocial-spectrum behavior was parsed out, the remaining variance in child abuse victimization may have related to anxious tendencies, hence to less persistent aggression.

It is important to note that our conceptual model is dimensional. We speculate that, while the most persistently aggressive men had higher scores on risk factors for life-course persistent antisocial behavior than their less persistent counterparts, these men do not likely belong to a population of lifelong antisocial individuals or those who exhibit antisocial personality disorder. Over $40 \%$ of our community sample of men who were physically aggressive at premarriage continued their aggression across all assessment periods. Such a rate of antisociality would be extremely high, even in samples selected for more extreme aggressivity. Life-course persistent antisocial individuals are thought to represent approximately $5 \%$ of delinquents (Moffitt, 1993), and antisocial personality disorder only occurs in approximately $1.5 \%$ of the population (Narrow et al., 2002).

The most persistently aggressive men in our sample were a heterogeneous group. A man who consistently pushed or grabbed his wife twice per year, as well as a man who consistently punched his wife every Friday night would both have qualified for the highest level of aggression persistence. To explore the performance of our set of risk factors in predicting the persistence of severe physical aggression, analyses were repeated in the more homogeneous subsample of men who were severely aggressive at premarriage. In bivariate analyses of this subset, only general aggression and the frequency of premarital physical aggression emerged as significant predictors of persistent severe aggression. Although the significance could not be tested, it should be noted the correlation of general aggression with the persistence of severe aggression was larger than the correlation of general aggression with the persistence of total physical aggression.
While the distribution our aggregate measure of persistence revealed - much to our surprise - that the most persistent level of aggression was also the most common, the distribution of the persistence of severe aggression roughly followed what one would expect in a community sample. The greatest number of men were severely aggressive at premarriage only, with successively declining numbers severely aggressive at two, three, and four of the assessment points. The most persistent two classes of severe aggressors (those severely aggressive at three or four of the assessment points) were represented by approximately $15 \%$ of the sample of 94 men who were aggressive at premarriage. This is still too high for all of these men to have been drawn from a population of life-course antisocial individuals. Moreover, persistent severe aggression was associated with few of the correlates of life-course persistent antisocial behavior. Furthermore, the finding of decreasing numbers of men as one moves up the severe aggression persistence continuum should be considered in light of our finding that a large group of men who were not severely aggressive at premarriage later became severely aggressive. Thus, there appear to be different developmental processes at work that move some men toward severe aggression, while moving others away from it. Due to the consequences of persistent severe aggression, future theoretical and empirical work should attempt to identify other predictors.

In conclusion, our findings indicate that many of the risk factors for persistent antisocial behavior are also modest, but useful, predictors of persistent male-to-female aggression in early marriage. The early identification of men at risk for persistent aggression toward their wives is of substantial practical significance for the counsel of women considering marriage, as well as for the design of programs for violence prevention and early intervention. The predictors utilized in the present investigation could be readily assessed in a typical clinical practice, and appear to provide valuable predictive information. Given the prediction of physical aggression found herein, if a clinician also knows about the man's family of origin aggression history, whether he is generally aggressive, and the degree of his aggression at premarriage, the clinician can help a client seeking relationship consultation to make informed choices. Furthermore, early treatment for marital aggression (e.g., O'Leary et al., 1999) might be recommended to prevent its persistence, even in cases where the presenting aggression is not particularly severe.

Although measures of antisociality were not available in our database, the fact that there was overlap in the predictors of aggression persistence and risk factors for persistent antisocial behavior suggest that antisociality 
may itself be predictive of persistent partner aggression. Future work in the area might address this relation. Emerging work on the role of antisocial characteristics in batterer subtypes (e.g., Babcock et al., in press) may be particularly useful in this regard.

An additional promising avenue for future research would be to consider dyadic husband-to-wife processes, with an emphasis on the multiple ways in which wives might influence the persistence of their husband's aggression. The frequency and persistence of wife-to-husband aggression seems like a good candidate. Male and female partner aggression are substantially associated $(r=.71$ in Lawrence \& Bradbury, 2001). Being aggressed upon by one's wife may be a trigger for continued aggression in young men. Moreover, the findings of Capaldi and Owen (2001) suggest that antisocial characteristics can be factors in female-to-male aggression in much the same way that they are in male aggression. Therefore, the risk factors found here to predict persistent male aggression may indeed be predictive of persistent female aggression. Multivariate models with larger samples could simultaneously estimate the relation of these predictors to the persistence female and male aggression, as well as between the measures of persistence in men and women.

Future studies would also benefit from more sensitive measures of the persistence of aggression. More frequent assessments would be especially useful in this regard. Consider the example of retrospective reports of aggression in 1 year intervals. If six acts of aggression are reported in a given year, did these all occur in one incident, or was the man aggressive once every other month? The latter is probably a better example of persistent aggression. Such fine-grained distinctions would be evident if aggression were assessed more frequently. Furthermore, memory distortions may be less likely or less severe when subjects are asked to recall events that have occurred in the more recent past, compared to recollections of events over the relatively long intervals we report here. Thus, more frequent assessments of aggression would address two of the methodological weaknesses of the present investigation, namely the low sensitivity of our persistence measure and the problems of recall of interpersonal events that occur over a long period.

Finally, the generalizability of our findings should be carefully considered. Our sample was representative of the White suburban/urban population from which it was drawn, but was somewhat more educated, averaging about 2.5 years of college education. One cannot necessarily generalize to older, non-White, low socioeconomic status, or treatment seeking couples. In addition to outright attempts to replicate the findings reported here, the knowledge base in the area would be improved by evaluating the replicability of our findings in samples that differ from the present one. Research on adolescent antisocial behavior, for example, has found that intrapersonal risk factors in high socioeconomic status groups do not function as such in low socioeconomic groups (Raine \& Venables, 1984). Contextual stressors and neighborhood factors may play more of a role in predicting antisocial behavior in disadvantaged youths. We would not be surprised to find such differences in the prediction of persistent aggression.

\section{ACKNOWLEDGMENTS}

The authors would like to thank Susan G. O'Leary for her helpful comments on earlier drafts of this manuscript.

\section{REFERENCES}

Aldarondo, E., and Sugarman, D. B. (1996). J. Consult. Clin. Psychol. 64: 1010-1019.

Babcock, J. C., Green, C. E., Webb, S. A. and Graham, K. H. (in press). A Second Failure to Replicate the Gottman et al. (1995). Typology of Men Who Abuse Intimate Partners and Possible Reasons Why. Journal of Family Psychology.

Boney-McCoy, S., and Finkelhor, D. (1996). Is youth victimization related to trauma symptoms and depression after controlling for prior symptoms and family relationships? A longitudinal, prospective study. J. Consult. Clin. Psychol. 64: 1406-1416.

Browning, J., and Dutton, D. (1986). Assessment of wife assault with the Conflict Tactics Scale: Using couple data to quantify the differential reporting effect. J. Marriage Fam. 48: 375-379.

Campbell, J. C., Kub, J., Belknap, R. A., and Templin, T. N. (1997). Predictors of depression in battered women. Violence Against Women 3: 271-293

Capaldi, D. M., Shortt, J. W., and Crosby, L. (2003). Physical and psychological aggression in at-risk young couples: Stability and change in young adulthood. Merrill-Palmer Quarterly, 49: 1-27.

Capaldi, D. M., and Owen, L. D. (2001). Physical aggression in a community sample of at-risk young couples: Gender comparisons for high frequency, injury, and fear. J. Fam. Psychol. 15: 425-440.

Crowell, N. A., and Burgess, A. W. (1996). Understanding Violence Against Women, National Academy Press, Washington, DC.

Elkins, I. J., Iacono, W. G., and Doyle, A. E. (1997). Characteristics associated with the persistence of antisocial behavior: Results from recent longitudinal research. Aggression Violent Behav. 2: 101-124.

Feld, S. L., and Straus, M. A. (1989). Escalation and desistance of violence in marriage. Criminology 27: 141-161.

Huesmann, L. R., Eron, L. D., Lefkowitz, M. M., and Walder, L. O. (1984). Stability of aggression over time and generations. Dev. Psychol. 20: 1120-1134.

Jackson, D. N. (1974). Personality Research Form Manual. Research Psychologists Press, Goshen, NY.

Jacobson, N. S., Gottman, J. M., Gortner, E., Berns, S., and Shortt, J. W. (1996). Psychological factors in the longitudinal course of battering: When do the couples split up? When does the abuse decrease? Violence Vict. 11: 371-392.

Lawrence, E., and Bradbury, T. N. (2001). Physical aggression and marital dysfunction: A longitudinal analysis. J. Fam. Psychol. 15: $135-154$.

Loeber, R., and Stouthamer-Loeber, M. (1998). Development of juvenile aggression and violence: Some common misconceptions and controversies. Am. Psychol. 53: 242-259. 
Lynam, D. R. (1996). Early identification of chronic offenders: Who is the fledgling psychopath? Psychol. Bull. 120: 209-234.

Moffitt, T. E. (1993). Adolescence-limited and life-course-persistent antisocial behavior: A developmental taxonomy. Psychol. Rev. 100: 674-701.

Moffitt, T. E., and Caspi, A. (2001). Childhood predictors differentiate life-course persistent and adolescence-limited antisocial pathways among males and females. Dev. Psychopathol. 13: 355-375.

Narrow, W. E., Rae, D. S., Robins, L. N., and Regier, D. A. (2002). Revised prevalence estimates of mental disorders in the United States. Arch. Gen. Psychiatry 59: 115-123.

O'Leary, K. D. (1999). Developmental and affective issues in assessing and treating partner aggression. Clin. Psychol. Sci. Pract. 6: 400414.

O'Leary, K. D., Barling, J., Arias, I., Rosenbaum, A., Malone, J., and Tyree, A. (1989). J. Consult. Clin. Psychol. 57: 263-268.

O'Leary, K. D., Heyman, R. E., and Neidig, P. H. (1999). Treatment of wife abuse: A comparison of gender-specific and conjoint approaches. Behav. Ther. 30: 475-505.

O'Leary, K. D., Malone, J., and Tyree, A. (1994). Physical aggression in early marriage: Pre-relationship and relationship effects. J. Consult. Clin. Psychol. 62: 594-602.
Olweus, D. (1979). Stability of aggressive reaction patterns in males: A review. Psychol. Bull. 86: 852-875.

Quigley, B. M., and Leonard, K. E. (1996). Desistance of husband aggression in the early years of marriage. Violence Vict. 11: 355-370.

Raine, A., and Venables, P. H. (1984). Tonic heart rate level, social class and antisocial behaviour in adolescents. Biol. Psychol. 18: $123-132$.

Riggs, D. S., and O'Leary, K. D. (1996). Aggression between heterosexual dating partners: An examination of a causal model of courtship aggression. J. Interpers. Violence 11: 519-540.

Schafer, J. L. (1999). NORM: Multiple imputation of incomplete multivariate data under a normal model (Version 2) [computer software], Author, University Park, PA.

Selzer, M. L. (1971). The Michigan Alcoholism Screening Test: The quest for a new diagnostic instrument. Am. J. Psychiatry 127: 8994.

Straus, M. A. (1979). Measuring intrafamily conflict and violence: The Conflict Tactics (CT) Scales. J. Marriage Fam. 41: 75-88.

Suitor, J. J., Pillemer, K., and Straus, M. A. (1990). Marital violence in a life course perspective. In Straus, M. A. and Gelles, R. J. (eds.), Physical Violence in American Families, Transaction Publishers, New Brunswick, NJ, pp. 305-317. 